\title{
Interitem time distribution and response compatibility in the short-term serial retention of digits ${ }^{1}$
}

\author{
GILBERT J. HARRIS AND BRADLEY LOWN \\ STATE UNIVERSITY OF NEW YORK AT BUFFALO
}

Twenty digits were presented sequentially during a $40 \mathrm{sec}$ display period. Three conditions of inter-item time distribution and three conditions of compatibility of answer sheet forms were employed in a 3 by 3 factorial design. The 20 digits were either distributed evenly over time, in two groups of 10 digits with a $20 \mathrm{sec}$ rest between groups, or in three groups of 6, 7, and 7 digits with 10 sec rests between groups. Three levels of compatibility consisted of answer sheets containing either 20 equally spaced answer blanks, two groups of 10 blanks, or three groups of 6, 7, and 7 blanks. Results showed an interaction between the two variables. In addition, serial position curves showed multi-bowing effects which suggested both input and output anchoring.

As early as 1896 (Ladd \& Woodworth, 1911) it was reported that when a list of stimuli is too long to be learned in a single trial, all items are not learned with equal speed. In general, those stimuli at the beginning and those at the end of the list are learned more quickly yielding the now familiar serial position learning curve. Dividing such a list of discrete items into parts during presentation, while still going through the entire list, was found to be most efficient with respect to retention.

Typically, in the study of the retention of serial lists, items are presented at regular time intervals. "However, recent studies strongly suggest that input 'chunking' is a critical variable which significantly affects the amount of information that is stored and subsequently retrieved." (Mayzner et al, 1966, p. 403). The inference was made and supported by Mayzner et al that distributing the input in different ways over time induces different chunking strategies. Digits were presented at the rate of one digit per sec, and the remaining $20 \mathrm{sec}$ of a $40 \mathrm{sec}$ interval were distributed in various ways. His results showed a systematic increase in retention with increased pauses during the presentation period. Serial position curves demonstrated multi-bowing effects from which it was concluded that input chunking was dependent upon inputtime distribution.

The present study will investigate three of the Mayzner et al distributions of items to see if and how retention is facilitated. In addition, investigation will be made of the effects of stimulus-response compatibility (Fitts \& Seeger, 1953) and an anchoring concept (Feigenbaum \& Simon, 1962) on the suggested retention and multi-bowing effects.

\section{Method}

The 60 Ss were introductory psychology students at the State University of New York at Buffalo and were fulfilling a course requirement.

The design was a 3 by 3 factorial with both factors, inter-item time distribution and response compatibility, manipulated as between Ss variables.

The apparatus used to generate the sequences of stimuli included a Bina-View display controlled by Grason-Stadler electronic modules. A closed circuit television system was used to present the items.

Eleven different pseudorandom sequences of 20 digits each were constructed with the restriction that each of the digits 0 through 9 be used once and only once in both the first and second halves of each of the sequences.

Three conditions of inter-item time distribution were investigated. In Condition $\mathrm{I}$, the 20 digits were presented at a 2 sec per digit rate. In Condition II, two groups of 10 digits each were presented at a $1 \mathrm{sec}$ per digit rate with a 20 sec rest between groups. In Condition III, three groups of 6,7 , and 7 digits were presented at a $1 \mathrm{sec}$ per digit rate with $10 \mathrm{sec}$ rests between groups. Thus, total display time (rest plus stimulus exposures) was constant across conditions.

Three groups of 20 Ss were run successively, one under each condition. Within each group of $20 \mathrm{Ss}$, there was a random assignment to one of three answer sheet groups. Answer sheet Type-1 consisted of 20 blanks of $1 / 4 \mathrm{in}$. each in a horizontal line with $1 / 8$ in. between blanks. Answer sheet Type-2 consisted of two groups of $101 / 4 \mathrm{in}$. blanks divided by a 1 in. space. Answer sheet Type-3 consisted of three groups of 6,7 , and $71 / 4 \mathrm{in}$. blanks with 1 in. spaces dividing the 20 blanks into three groups.

For each of the three conditions, all 20 Ss were seated in a classroom with a clear view of the television receiver. The Ss were given one practice sequence and 10 experimental sequences with $15 \mathrm{sec}$ between the end of each $75 \mathrm{sec}$ recall period and the onset of the next sequence.

\section{Results}

The mean number of digits correctly recalled in proper serial position was recorded for each of the nine treatment conditions. These results are indicated in Fig. 1. There was a simple effect of a linear 


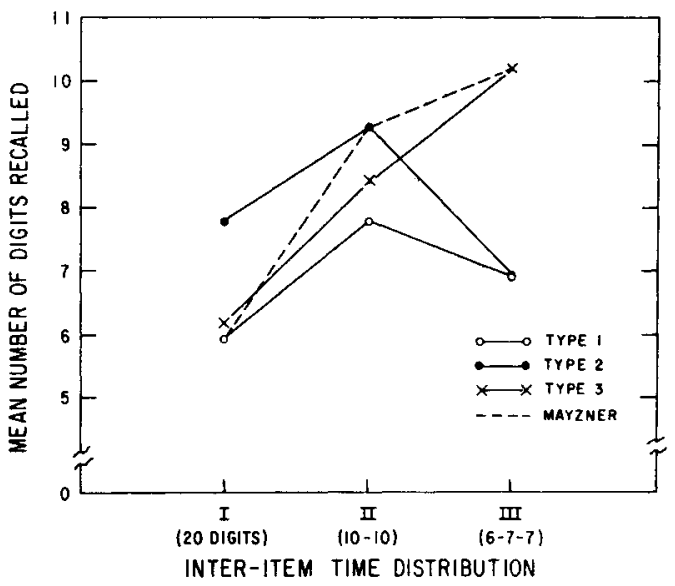

Fig. 1. Mean number of digits recalled in proper serial order as a function of inter-item time distribution.

increase at the Type-3 answer sheet compatibility level $(F=57.28$, df $=1 / 17, p<.001)$. In addition, there was also a systematic linear increase in mean number correctly recalled if the three treatment conditions corresponding to Mayzner et al (1966) were considered $(F=32.15, d f=1 / 17, p<.001)$. The main effect of interitem time distribution was significant $(F=10.60$, df $=2 / 51, p<.001$ ), but there was no systematic increase from Conditions I to III. The main effect of compatibility of answer sheets was significant also $(F=6.13$, $\mathrm{df}=2 / 51, \mathrm{p}<.01$ ). The interaction between inter-item distribution and answer sheet compatibility was significant $(F=5.68, \mathrm{df}=4 / 51, \mathrm{p}<.01)$.

Figure 2 contains the serial position curves for the three inter-item time distributions. In Conditions II and III, it is evident that the predicted multi-bowing

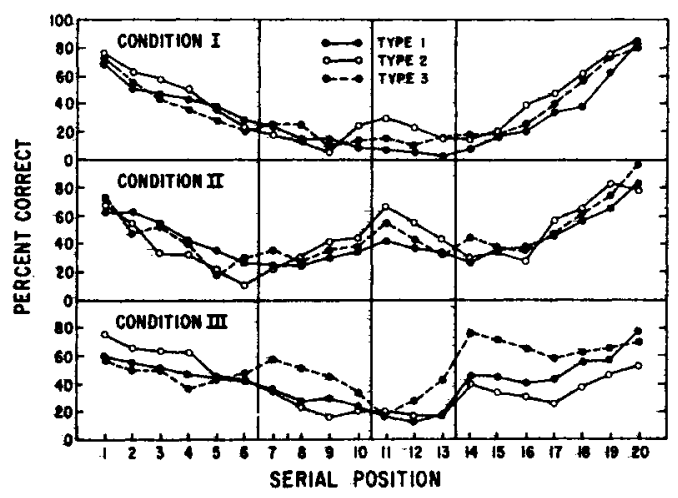

Fig. 2. Serial position curves for Conditions I - III. effects were most strikingly demonstrated in combination with the corresponding answer sheet (i.e., Condition III and answer sheet Type-3). The serial position curve for Condition $I$ indicates an effect of the Type-2 answer sheet independent of interitem time distribution.

\section{Discussion}

The Mayzner et al (1966) result that certain timing distributions can yield marked and systematic increases in total amount of information retrieved (i.e., items correct) was replicated, but the interaction between compatibility of answer sheet and inter-item time distribution suggests that the effect of compatibility upon information retrieval is more formidable under the Condition III input distribution. The Mayzner et al study assumed no such interaction.

The facilitative effect of input Conditions II and III may be better understood as a grouping effect due to additional anchor points (Feigenbaum \& Simon, 1962) rather than as chunking which implies a newly coded unit. The obtained interaction suggests that with compatible input-output conditions, these anchor points are strengthened. In Condition $I$, where inter-item time distribution provides no anchor points (other than the first and last item), increased recall with Type-2 and Type-3 answer sheets supports the conclusion that such anchor points may be developed as a function of output strategies alone. In addition, clear remnants of a triple-bowed effect with the Type-3 answer sheet in Condition II and a doublebowed effect with the Type-2 answer sheet in Condition I provide further support for this conclusion.

The present results suggest that grouping or anchoring effects in terms of output as well as input must be considered in the analysis of serial recall. Further, it is not always obvious which response strategy is the most compatible and efficient.

\section{References}

FEIGENBAUM, E. A., \& SIMON, H. A. A theory of the serial position effect. Brit. J. Psychol, 1962, 53, 307-320.

FITTS, P. M., \& SEEGER, C. M. S-R compatibility: spatial characteristics of stimulus and response codes. J. exp. Psychol, 1953, 46, 199-210.

LADD, G. T., \& WOODWORTH, R. S. Elements of physiological psychology, New York: Charles Scribner's Sons, 1911, 577-578.

MAYZNER, M. S., TRESSELT, M. E., ADLER, S., COHEN, A., \& SCHOENBERG, K. M. Short-term retention of digits: a function of jtem distribution with respect to time. Psychon. Sci, 1966, 5, 403-404.

Note

1. This research was partially supported by USPHS Grant MH-11595

to Dr. Kenneth R. Laughery under whose direction this project was carried out. 